\title{
España ante la invasión alemana y soviética de Polonia en septiembre de 1939
}

\author{
Bartosz KACZOROWSKI \\ Universidad de Łódź, Polonia \\ bartoszkaczorowski@wp.pl
}

Recibido: $17 / 12 / 2012$

Aceptado: 10/06/2013

\section{RESUMEN}

Este artículo analiza las reacciones políticas que en España generó la invasión de Polonia, tanto por parte alemana, el 1 de septiembre de 1939, como por parte soviética, dieciséis días después. Comienza con el análisis que el régimen de Franco hizo del pacto Ribbentrop-Molotov, que propició la invasión y el posterior reparto del territorio polaco entre Alemania y la Unión Soviética. Prosigue con las reacciones generadas por la invasión de Alemania, y se cierra con las que propició el ataque soviético. Todo ello, sobre la base de documentación española, alemana, portuguesa, estadounidense y polaca, así como del análisis de memorias de políticos testigos de lo acaecido, y de la prensa española del momento.

Palabras clave: Polonia, España, Tercer Reich, URSS, Segunda Guerra Mundial.

\section{Spain Towards the German and Soviet Invasion of Poland}

\begin{abstract}
This article analyzes the political reactions of the Spanish Government towards invasion of Poland made both by Germany, on September 1, 1939, and by the Soviets sixteen days later. It begins with the analysis of Spanish attitude towards the Molotov-Ribbentrop Pact, which led to the invasion and the subsequent division of Polish territory between Germany and the Soviet Union. It continues with the reaction of Francoist Government on German attack and closes with analysis of Spanish approach to the Soviet attack. The article is based on Spanish, German, American, Portuguese and Polish documentation, on the memories of the politicians, and on the Spanish press of these times.
\end{abstract}

Key words: Poland, Spain, Third Reich, USRR, Second World War.

Referencia normalizada: Kaczorowski, B. (2013). “España ante la invasión alemana y soviética de Polonia en septiembre de 1939”. Cuadernos de Historia Contemporánea, 35, pp. 177-192.

Sumario: Introducción. 1. España frente el Pacto Molotov-Ribbentrop 2. El estallido de la Segunda Guerra Mundial 3. Madrid ante la invasión del 17 de septiembre 4. Conclusiones 5. Referencias bibliográficas. 


\section{Introducción}

El estallido de la Segunda Guerra Mundial fue una mala noticia para España puesto que, a tan sólo cinco meses de finalizar la Guerra Civil, se encontró ante un nuevo conflicto. Además, a la conflagración entraron países cuyas políticas tenían gran influencia sobre España. Dos de ellos eran vecinos: Francia, por los Pirineos y Marruecos, y el Reino Unido, vía Gibraltar. Alemania, a su vez, había sido aliado de Franco durante la Guerra Civil, en tanto que la Unión Soviética todo lo contrario: su peor enemigo. No resulta extraño, entonces, el hecho de que los acontecimientos que tuvieron lugar en Polonia en 1939 llamasen la atención del Gobierno español, aunque tomase la decisión de no unirse al conflicto, al menos en aquel momento.

No hay duda de que la Guerra Civil, recientemente terminada, tuvo un tremendo impacto en la actitud de los españoles. Después de casi mil días de lucha sangrienta, el país quedó devastado. La destrucción, la crisis económica, las epidemias y las olas de hambre obligaron al Gobierno español a concentrarse en los problemas internos y obstaculizaron, en gran medida, su participación activa en la política exterior. Además, el campo de maniobra diplomática estaba limitado también por las relaciones internacionales creadas durante la Guerra Civil. Ante el apoyo decisivo a los franquistas del Eje, el Gobierno español debía pagar sus deudas materiales, y peor aún, también las morales.

Dado que la ayuda de Alemania durante la Guerra Civil contrastaba evidentemente con las partidistas neutralidades de Gran Bretaña (por muy escorada que estuviese hacia Franco) y Francia (decantada hacia la República), los políticos españoles mostraban reservas hacia la primera, por Gibraltar, y despreciaban a Francia. Tampoco podían olvidar la activa participación de la Unión Soviética en favor de la República, por lo que la consideraban su enemigo principal, peligroso no sólo para España, sino para el futuro de Europa. Por esas razones el general Francisco Franco se decantó por materializar una política pro-alemana, pero esto no significaba el abandono de las aspiraciones de llevar su propio juego en el ámbito europeo. Por lo tanto, la diplomacia española tuvo que combinar hábilmente la lucha en interés del Estado franquista y la no entrada en un conflicto con el Tercer Reich ${ }^{1}$. Y precisamente, la política española hacia la agresión alemana y soviética a Polonia en septiembre de 1939 fue un intento de encontrar un punto medio. ${ }^{2}$

Este artículo se basa en documentación oficial, tanto de la diplomacia española como de los países interesados en la política llevada a cabo por el gobierno del general Franco en el año 1939. En primer lugar, cabe destacar el uso de fuentes

1 Sobre las relaciones entre España y Alemania en la primera fase de la Segunda Guerra Mundial veáse también: BURDICK, Charles: Germany's Military Strategy and Spain in World War II, New York, Syracuse University Press, 1968; MORENO JULIÁ, Xavier: Hitler y Franco. Diplomacia en tiempos de guerra (19361945), Barcelona, Editorial Planeta, 2007; PAYNE, Stanley: Franco y Hitler : España, Alemania, la Segunda Guerra Mundial y el holocausto, Madrid, La Esfera de los Libros, 2008; ROS AGUDO, Manuel: La guerra secreta de Franco (1939-1945), Barcelona, Editorial Crítica, 2002.

2 Un artículo interesante sobre las relaciones entre España y Polonia en la Segunda Guerra Mundial fue escrito por Wayne H. Bowen. BOWEN, Wayne H: "Spain and the Nazi occupation of Poland, 1939-44", en International Social Science Review, 2007, vol. 82, pp. 135-148. Sin embargo, la reacción española ante el estallido de guerra no fue objeto de su análisis profundo. 
primarias, fruto de las consultas en el Archivo del Ministerio de Asuntos Exteriores de Madrid. Además, se han utilizado las recopilaciones de documentos sobre la política exterior de: Alemania (Documents on German Foreign Policy), Estados Unidos (Foreign Relations of the United States) y Portugal (Dez Anos de Politica Externa y Correspondência de Pedro Teotónio Pereira para Oliveira Salazar). Resultaron ser un complemento muy valioso también: los artículos de periódicos españoles (Arriba, $A B C$, La Vanguardia Española), las memorias de los testigos oculares de aquellos acontecimientos (Francisco Gómez Jordana, José María Doussinague y Alexander Cadogan) y monografías sobre la política exterior de España.

\section{España frente el Pacto Molotov-Ribbentrop}

El Pacto de No Agresión germano-soviético del 23 de agosto de 1939 fue recibido por todos los españoles (vencedores y vencidos) con incredulidad, y la mejor evidencia, por lo que a los vencedores respecta, es el título de un artículo del diario falangista Arriba: "Sorpresa. Tremenda sorpresa". ${ }^{3}$ De golpe, el país considerado por España la principal fuerza capaz de defender Europa contra el bolchevismo acababa de convertirse en aliado del país que lo detentaba como dogma. Una reconciliación de las dos partes enfrentadas en la Guerra Civil que iba a obligar a Franco a dar respuesta a Alemania por su radical cambio de política exterior.

A nivel propagandístico, el acuerdo fue considerado como "un triunfo del realismo", expresión que hacía hincapié en su carácter coyuntural. ${ }^{4}$ Sin embargo, no se puede ocultar que la nueva realidad fue una gran sorpresa para los políticos españoles y que durante mucho tiempo no supieron cómo reaccionar ante aquellos acontecimientos. Franco, por temor a empeorar las relaciones con el Tercer Reich, dejó de manifestar su anticomunismo, y comenzó a hacer hincapié en que el acuerdo con los soviéticos constituía solamente una respuesta a las conversaciones mantenidas entre Gran Bretaña y la República Soviética en agosto de 1939.

A pesar de que era recomendable presentar una actitud moderada, los políticos españoles no consiguieron ocultar su disgusto por el tratado concluido, que se notó inmediatamente en el ámbito internacional. El embajador de Madrid en Washington, Francisco Cárdenas, en una conversación con el subsecretario de Estado estadounidense, Sumner Welles, admitió abiertamente que el prestigio de Alemania en España había disminuido considerablemente después de la firma del Pacto. ${ }^{5}$ Por otra parte, Philippe Pétain, el famoso vencedor de Verdún y en 1939 embajador francés en Madrid, fue informado, entre otras cosas, de que España entendía su firma como un acto de liberación de toda obligación de apoyar el Tercer Reich en el caso de un posible conflicto con Francia. ${ }^{6}$

\footnotetext{
3 MORENO JULIÁ Xavier: Hitler y Franco..., p. 111.

4 MULARSKA-ANDZIAK, Lidia: Hiszpania w polityce Stanów Zjednoczonych w okresie Drugiej Wojny Światowej, Varsovia, 1990, p. 98.

5 Foreign Relations of the United States (en adelante, FRUS), 1939, vol. II, Washington 1956, p. 818-819: Transcripción de la conversación entre Sumner Welles y Francisco Cárdenas, 29/11/1939.

6 FRUS, 1939, vol. I, p. 365: Bullitt a Hull, 25/08/1939.
} 
En aquellas particulares circunstancias, la relación entre París y Madrid comenzó a hacerse más cordial. El ministro de Asuntos Exteriores francés, Georges Bonnet, durante una reunión con el embajador de los Estados Unidos, William Christian Bullitt, confirmó que la mejora de las relaciones mutuas progresaba "extremadamente rápido" y que el primer ministro, Édouard Daladier, había manifestado, medio en broma y medio en serio, que la única persona que podía disuadir a Mussolini de la estrecha alianza con Hitler era Franco ${ }^{7}$. Además, el jefe del Gobierno francés habló muy positivamente sobre la política del dictador español también durante sus conversaciones con el primer ministro británico, Neville Chamberlain, el 12 de septiembre de $1939 .^{8}$

El embajador de Bélgica aprobó también la actitud de las autoridades de Madrid y después de una reunión con el ministro español de Asuntos Exteriores, coronel Juan Beigbeder, dijo que aunque aquél se distanciaba de la crítica explícita del Pacto, había expresado "su gran indignación". ${ }^{9}$ Cabe destacar el hecho de que los políticos españoles respaldaron la iniciativa del rey de Bélgica, Leopoldo II, al apelar a que se tomasen medidas para proteger Europa del desastre de la guerra pero que, por razones políticas, y para no irritar a Alemania, decidió abstenerse de emitir cualquier declaración pública al respecto. ${ }^{10}$ Además, Beigbeder aseguró por vía privada al embajador de los Estados Unidos que España simpatizaba con las acciones del presidente Roosevelt, quien también pidió a las partes que negociasen la paz. ${ }^{11}$

En cuanto a los portugueses, evaluaron de otra forma la reacción española ante el Pacto entre Alemania y la Unión Soviética. Así, Franco se reunió con el embajador en Madrid, ya el 23 de agosto, inmediatamente después de recibir la información sobre el Pacto. Entonces Pedro Teotónio Pereira declaró que su firma constituía "la última prueba de la ausencia de cualquier ideología común entre nuestros países y Alemania" y que había llegado el momento de perder la ilusión de que Hitler iba a tratar el Pacto Antikomintern como fundamento de su política exterior. ${ }^{12}$ Según la correspondencia del embajador, Franco se abstuvo en su respuesta de hacer juicios firmes, pero no defendió la actitud de Alemania. Expresó sus condolencias a los polacos, y le manifestó que si no cedían a las exigencias de Hitler, se quedarían solos. Añadió además que la situación en Europa podría ser diferente si el Reino Unido hubiera fortalecido sus relaciones con los países del sur de Europa: Portugal, España e Italia. Sin embargo, dio más bien una mala impresión al embajador, que no ocultó que esperaba una reacción diferente ante los acontecimientos de Moscú, e incluso mencionó que ningún miembro del Gobierno había hablado en términos tan favorables para el Eje. ${ }^{13} \mathrm{Y}$ le resultó sorprendente que no considerase el Pacto "algo escandaloso". ${ }^{14}$

7 FRUS, 1939, vol. I, pp. 377-378: Bullitt a Hull, 27/08/1939.

8 DILKS, David (ed), The Diaries of Sir Alexander Cadogan 1938-1945, New York, G. P. Putnam's Sons, 1972, p. 216.

9 FRUS, 1939, vol. I, p. 374: Weddell a Hull, 26/08/1939.

10 Ibidem.

11 Ibidem.

12 Correspondência de Pedro Teotónio Pereira para Oliveira Salazar (1931-1939), vol. I, Lisboa 1987: Teotónio Pereira a Salazar, 25/08/1939, p. 193.

13 Ibidem, p. 195

14 Ibidem. 
El Pacto Ribbentrop-Molotov fue recibido con incredulidad también por la prensa española, que más bien no le daba suficiente importancia y predecía que no iba a cambiar la política de los dos países de forma significativa. El periodista de $L a$ Vanguardia Española, Augusto Assia, lo valoró como un mero pacto de no agresión, que no amenazaba Europa Central y del Este, pero que, sin embargo, constituía una desgracia para Gran Bretaña y Francia, ya que a pesar de sus muchos intentos de comunicarse con Stalin, estos países no habían conseguido lo que Ribbentrop durante su corta visita a Moscú. ${ }^{15}$ La actitud pro-alemana de los diarios españoles fue visible también el 25 de agosto, cuando el mismo periódico publicó un artículo que informaba sobre el despliegue de una división polaca en la zona de Gdansk, lo que, según su autor, constituía una prueba de que Polonia se preparaba para un ataque inmediato contra la Ciudad Libre de Dánzig. ${ }^{16} \mathrm{Al}$ mismo tiempo había en la prensa opiniones favorables para Polonia. Así, el artículo de Sofía Casanova publicado en $A B C$ el 25 de agosto contenía elogios a Polonia y remarcaba los elementos comunes con España: su catolicismo tradicional y la experiencia de haber ganado "la lucha contra el comunismo", en Polonia en 1920 y en España entre 1936 y 1939. ${ }^{17}$

Sin embargo, parece ser que la mejor descripción de la reacción española hacia el Pacto Molotov-Ribbentrop vino de la mano de la prensa del Vaticano. Así, L'Osservatore Romano, el 24 de agosto escribía: "España, un país que hizo la guerra más sangrienta contra el comunismo y se ha adherido al Pacto Anti-Komintern, mantiene su reserva frente a la nueva política alemana hacia Rusia". ${ }^{18}$ Esta "reserva" era el resultado de la traición de los ideales anticomunistas por Hitler al pactar con un país que, para los políticos de Madrid, era símbolo de la barbarie asiática y el peor enemigo, no sólo de España, sino de toda la civilización europea.

A pesar de la indignación, Franco y sus colaboradores optaron por no criticar abiertamente el Pacto, fundamentalmente por la manifiesta debilidad de España, destruida por la guerra y necesitada de paz, externa e interna y, por ello, de mantener buenas relaciones con el Tercer Reich. Cabía no olvidar que Berlín había proporcionado una ayuda inestimable durante la Guerra Civil, aunque en aquel momento comenzase a hacerse con la hegemonía europea. Pero, aun así, hubo políticos que evaluaron negativamente el Pacto y predijeron sus consecuencias al valorarlo como anuncio de la caída de Polonia. El embajador español en Londres, Jacobo Fitz-James Stuart y Falcó, Duque de Alba, en su informe presentado a Beigbeder, declaró que su tercer artículo, cuyo contenido fijaba consultas mutuas en cuestiones de interés común para los dos países, podía referirse a la toma de una posición única respecto a la situación de Polonia. ${ }^{19}$

15 ASSIA, Augusto: “Alemania rompe el frente enemigo. De la paz forzada a la paz tratada”, en $L a$ Vanguardia Española, 23/08/1939, p. 4.

16 "Enormes movimientos de fuerzas mientras los representantes alemanes abandonan Varsovia", en $L a$ Vanguardia Española, 25/08/1939, p. 4.

17 CASANOVA, Sofia: “ABC en Varsovia. La espera trágica”, en $A B C, 25 / 08 / 1939$, p.8.

18 Cita de L'Osservatore Romano: "España sobre el Pacto según el Órgano de Vaticano", en $A B C$, 25/08/1939, p. 6.

19 Archivo del Ministerio de Asuntos Exteriores, Madrid (en adelante, AMAE), R 1083/13: Alba a Beigbeder, 28/08/1939. 
Antonio Magaz, embajador de España en Berlín, acertó más aún al evaluar el papel que jugaba el Pacto. En su informe de 25 de agosto de 1939 dijo que era muy posible que en Moscú se hubiesen concluido acuerdos secretos. ${ }^{20}$ Lo valoraba como muy negativo para España, pues amenazaba la paz, elemento fundamental para el joven Estado franquista. Magaz predijo también que Polonia no haría ninguna concesión y, fiel a sus valores, lucharía contra los alemanes hasta el final: "En resumen -dijo-: Hemos llegado al punto crítico (....). Los pueblos esperan todavía una intervención para evitar una guerra generalizada. Se habla del Papa, de Roosevelt y del mismo Stalin, pero, al mismo tiempo, no se sabe cómo ha de ser esta intervención para que tenga alguna eficacia y consiga evitar la catástrofe que se acerca de hora en hora...". ${ }^{21}$ También vale la pena señalar que el embajador fue una de las pocas personas para las cuales el Pacto no constituyó una gran sorpresa. Hablando con Ramón Garriga, admitió que era consecuencia lógica de las bases ideológicas de dos sistemas totalitarios, en tanto que lo que más se parecía al comunismo soviético era "el nacionalsocialismo alemán". ${ }^{22}$

España prefería no participar en el conflicto ya que una nueva guerra podría convertirse en una tragedia para el país. El 21 de agosto, Beigbeder aseguró a Pétain que, en caso de estallar un conflicto entre Francia y Alemania, Madrid mantendría la neutralidad. Otra evidencia de las diferencias entre España y las potencias del Eje fue el hecho de que el ministro, en una reunión con el embajador de Alemania, Eberhard von Stohrer, admitió abiertamente que no encontraba culpa alguna en Polonia que justificase una intervención contra ella. ${ }^{23}$ Sin embargo, España no podía criticar la política alemana de fuerza, pues debía mantener con ella la mejor relación posible, primero, como se ha dicho ya, por las ayudas recibidas durante la Guerra Civil, y segundo, por el crecimiento de la posición del Tercer Reich en el ámbito internacional.

\section{El estallido de la Segunda Guerra Mundial}

La noticia sobre la invasión alemana de Polonia provocó en España reacciones decididamente negativas. Desde el principio los políticos españoles eran conscientes de que otra guerra podía ser destructiva para España. "¡Dios ayude a España y la proteja evitando que entre en este conflicto, pues ello sería catastrófico para nosotros!", palabras dramáticas que apuntó en su diario el ex ministro de Asuntos Exteriores, el general Francisco Gómez-Jordana. ${ }^{24}$ Sin embargo, el Gobierno español se mostró pragmático ante la agresión de la Wehrmacht. Beigbeder la utilizó como una excusa para negarse a firmar con Alemania un acuerdo cultural desfavorable. ${ }^{25}$ De este

20 AMAE R 1188/3: Magaz a Beigbeder, 25/08/1939.

21 Ibidem.

22 GARRIGA, Ramón: La España de Franco. Las relaciones con Hitler, Madrid, G. del Toro Editor, 1976 , p. 113.

23 SUÁREZ FERNÁNDEZ, Luis: Franco, España y la Segunda Guerra Mundial, Madrid, Actas, 1997, p. 107.

24 GÓMEZ-JORDANA SOUZA, Francisco: Milicia y diplomacia, Burgos, Dossoles, 2002, p. 131.

25 ÁlVAREZ BOLADO, Alfonso: Para Ganar la Guerra, para Ganar la Paz: Iglesia y Guerra Civil: 1936-1939, Madrid, Publicaciones de la Universidad Pontificia Comillas, 1995, p. 483. 
modo, España impidió la entrada en vigor de un acuerdo que preveía la introducción de las prácticas totalitarias alemanas en el ámbito de cultura y la propaganda, y que fue abiertamente criticado tanto por los obispos españoles como por el Vaticano. ${ }^{26} \mathrm{Sin}$ embargo, al principio España se negó a evaluar claramente los acontecimientos que tuvieron lugar el 1 de septiembre. El Consejo de Ministros decidió emitir solamente una declaración que decía: "el Gobierno, que ha examinado la grave situación creada en el Oriente europeo, sigue con la mayor atención, en cada momento, el curso de los acontecimientos". ${ }^{27}$

El 3 de septiembre Gran Bretaña y Francia declararon la guerra al Tercer Reich, lo que significaba que el conflicto adquiría, además de un nivel regional en el este de Europa, nivel europeo en su conjunto. En vista de ello Franco emitió un comunicado en la radio, en el cual hizo un llamamiento para poner un pronto fin a la guerra y proceder de inmediato a negociaciones de paz:

Con la autoridad que me da el haber sufrido durante tres años el peso de una guerra para la liberación de mi Patria, me dirijo a las naciones en cuyas manos se encuentra el desencadenamiento de una catástrofe sin antecedentes en la Historia, para que eviten a los pueblos los dolores y tragedias que a los españoles alcanzaron (...), horrores que serían centuplicados en una nueva guerra. (...). Su extensión, sin beneficio para los beligerantes, produciría hondísima e insuperable perturbación en la economía del mundo, pérdida incalculable en su riqueza y paralización de su comercio, con grave repercusión en el nivel de la vida de las clases humildes. En estas condiciones, apelo al buen sentido y responsabilidad de los gobernantes de las naciones para encaminar los esfuerzos de todos a localizar el conflicto actual. ${ }^{28}$

Aquel llamamiento se produjo tras previa consulta con Italia. Según algunos investigadores, es una prueba de que Franco jugó en interés de los países del Eje. ${ }^{29}$ Sin embargo, parece ser que su principal objetivo fue evitar la extensión de la guerra al oeste y al sur de Europa, lo que supondría una amenaza para España. Además, en Madrid no se ocultaba el hecho de que aquel conflicto podía fortalecer seriamente a la Unión Soviética, la cual se beneficiaría de la caída de las naciones occidentales. "Esta guerra no la ganará nadie más que la URSS", dijo un alto funcionario del Ministerio de Asuntos Exteriores, José María Doussinague, al oír la noticia de la invasión alemana de Polonia. ${ }^{30}$

De acuerdo con las previsiones anteriores, Franco declaró la neutralidad de España en la guerra el 4 de septiembre 1939. El contenido de la declaración fue el siguiente: "Constando oficialmente el estado de guerra que, por desgracia, existe entre

26 Carta de monseñor Cicognani al cardenal Gomá, 23/03/1939, en el Archivo Gomá. ANDRÉSGALLEGO José y PAZOS Antón (ed.), Documentos de la Guerra Civil, vol. 13 (enero-marzo 1939), Madrid, Consejo Superior de Investigaciones Cientificas, 2010, p. 34.

27 "Interesante Consejo de ministros", en La Vanguardia Española, 02/09/1939, p. 1. "El Consejo de ministros de ayer", en $A B C, 02 / 09 / 1939$, p. 7.

28 "El noble llamamiento del Caudillo", en $A B C, 05 / 09 / 1939$, p. 7.

29 TUSELL, Javier: Franco y Mussolini. La politica española durante la segunda guerra mundial, Barcelona, Ediciones Península, 1985, p. 81.

30 DOUSSINAGUE, José María: España tenía razón, Madrid, Espasa - Calpe S.A, 1949, p. 12. 
Inglaterra, Francia y Polonia, de un lado, y Alemania de otro, ordeno por el presente decreto la más estricta neutralidad a los súbditos españoles, con arreglo a las leyes vigentes y a los principios de Derecho público internacional". ${ }^{31}$

Los gobiernos europeos respaldaron esta declaración. El Reino Unido quedó satisfecho con la noticia de que el control que guardaba sobre la entrada al Mediterráneo, es decir sobre Gibraltar, no estaba amenazado; Francia, también, en tanto que no quedaba amenazada por la posibilidad de un ataque desde el otro lado de los Pirineos. ${ }^{32}$ También vale la pena señalar que, en contraste con la actuación de Benito Mussolini, Franco decidió ser neutral, no sólo "no beligerante". Este fue un indicio importante para ambas partes ya que indicaba que, después de casi tres años de lucha, España quería protegerse sobre todo contra otro posible conflicto armado.

En aquella línea de acción, Franco participó en los esfuerzos para lograr la reconciliación de las partes. El 29 de agosto, es decir, antes del estallido del conflicto, el ministro de asuntos exteriores francés, Georges Bonnet, partidario de la paz y defensor de la política de Appeasement (apaciguamiento), pidió a los españoles que convenciesen a Hitler y así salvasen Europa de la guerra. ${ }^{33}$ Bonnet aseguró que esta propuesta contaba con el apoyo del gobierno francés y británico, pero muy pronto resultó evidente que la persona más importante, la que debería dar su consentimiento en este caso, era Adolf Hitler. Franco consciente de las limitaciones de su posición, decidió consultar primero con Mussolini. Éste no respaldó la propuesta, pues no quiso que Franco conquistase fama por haber llevado a cabo el proceso de mediación. El 30 de agosto, el ministro de Asuntos Exteriores italiano, conde Galeazzo Ciano, dio una respuesta negativa al embajador español, por lo que la posibilidad de realizar un último intento de mediación no se aprovechó. ${ }^{34}$ Otra cosa es que Franco recelase de presentar la cuestión con coraje y, pese a la negativa italiana, apelar directamente a los países involucrados en el conflicto. Pero no debe olvidarse, una vez más, que tenía una deuda de gratitud con los líderes de los países del Eje, derivada de los tiempos de la Guerra Civil, y en gran parte fue por ello que tuvo miedo de presentar ciertos temas en público.

El transcurso de la invasión alemana de Polonia en septiembre 1939 fue bastante preocupante para España. La victoria inmediata de la Wehrmacht podría significar la extensión de la guerra hacia el oeste y el sur y, además, la derrota de Polonia hacía cada vez más probable el peligro de que la Unión Soviética se uniese al conflicto para ocupar una parte del territorio polaco. Un conjunto de posibilidades que se exponían en la carta que Franco envío el 6 de septiembre al embajador en Italia, y que decía: "La situación del oriente de Europa permite vislumbrar una próxima intervención Rusia en Polonia [para provocar] su reparto. Veinte millones de católicos

31 "El Jefe del Estado ordena la más estricta neutralidad a los súbditos españoles", en $A B C, 05 / 09 / 1939$, p. 7.

32 Dez Anos de Politica Externa: a Nação Portuguesa e a Segunda Guerra Mundial (en adelante, DAPE), vol. 6, Lisboa 1971, p. 28: Monteiro a Salazar, 04/09/1939.

33 TUSELL, Javier: Franco, España y la Segunda Guerra Mundial, Madrid, Ediciones Temas de Hoy, 1995, p. 47.

34 Idem, Franco y Mussolini..., p. 80. 
serían entregados a los comunistas". ${ }^{35}$ La única posibilidad para evitar aquella situación, según Franco, era la capitulación de Polonia antes de que Stalin aprovechase la oportunidad de extender su influencia hacia el Oeste. Por ello, a pesar de la negativa declarada anteriormente por Italia, España no dejó de hacer esfuerzos para lograr la reconciliación entre las dos partes en conflicto.

El 5 de septiembre por la tarde, Beigbeder informó a Teotónio Pereira que Franco iba a pedir al Vaticano, Italia, Gran Bretaña y Francia que convenciesen a Polonia sobre la necesidad de rendirse y comenzar las negociaciones de paz antes de que la intervención de Rusia llevase "a la destrucción de este estado católico y al martirio de sus habitantes" ${ }^{36}$. Al día siguiente, Nicolás Franco, el hermano del dictador, entonces embajador en Lisboa, le pidió al primer ministro portugués, António de Oliveira Salazar, que apoyara los planes de España de limitar el conflicto. La respuesta de Salazar fue positiva e inmediatamente envió la siguiente declaración a Madrid: "El llamamiento de Vuestra Excelencia tiene toda mi simpatía. Haré todo lo posible para ampliar la zona de paz y trabajar por el bien de la humanidad". ${ }^{37}$ Pero al cabo de unos días se hizo evidente que España no daba pasos importantes y, además, se supo que el embajador británico en San Sebastián ni siquiera fue informado sobre la acción. ${ }^{38} \mathrm{La}$ falta de iniciativa española fue destacada también por el Secretario de Estado británico del Foreign Office, Orme Sargent, durante la reunión con el embajador portugués en Londres ${ }^{39}$.

Beigbeder presentó al Jefe de Estado en octubre un informe sobre su actividad, explicando con bastante precisión la actitud inestable de la diplomacia española. Mencionó que la propuesta de la mediación de paz presentada por España no fue prioritaria para el país por temor a empeorar las relaciones con el Tercer Reich. Admitió sinceramente, además, que la posición internacional de España no era sencilla, ya que sólo podía contar con la ayuda de tres países, Portugal, Italia y el Vaticano y, por tanto, su capacidad de llevar a cabo una política europea activa era muy limitada. ${ }^{40}$

Mientras el Gobierno fue moderado en cuanto a los acontecimientos que tenían lugar a orillas del Vístula, la sociedad española manifestó en diversas ocasiones su simpatía por el país atacado. Incluso los medios de comunicación, muy dependientes del Gobierno y de la actividad del agregado de prensa alemán, Hans Lazar, mostraban señales amistosas hacia Polonia. Así, Arriba expresó el 8 de septiembre su admiración por el heroísmo de los soldados polacos:

En ocho días el heroísmo polaco, frente a frente con el ejército del Reich, ha perdido la capital de Polonia [falso], y con ella las mejores ciudades de la nación. Honor al pueblo polaco que, carente de toda ayuda, ha defendido con las armas un criterio

35 Ibidem, p. 82.

36 DAPE, vol. VI, p. 36: Salazar a Monteiro, 06/09/1939.

37 DAPE, vol. VI, p. 37: Salazar a Pereira, 06/09/1939.

$38 D A P E$, vol. VI, p. 45: Salazar a Monteiro, 09/09/1939.

39 DAPE, vol. VI, p. 48: Monteiro a Salazar, 12/09/1939.

40 SUÁREZ FERNÁNDEZ, Luis: España, Franco..., p. 119. 
político que la Historia calificará en su justo sentido, y a quien hoy toda la prensa de la gran Alemania rinde testimonio de admiración! ${ }^{41}$

Sin embargo, hay que destacar que en los periódicos españoles no se encuentra ninguna crítica de la política alemana hacia los polacos, ni evaluación de la invasión nazi, la cual fue evidentemente mucho más allá de lo que son territorios considerados como disputados. Ramón Garriga, favorable hacia el nuevo sistema, evaluó esta actitud de la prensa (y del gobierno, que tenía un tremendo impacto en lo que se escribía) como primera gran página vergonzosa que la España franquista escribió en el triste capítulo de sus relaciones internacionales". ${ }^{42}$

\section{Madrid ante la invasión del 17 de septiembre}

Aunque el ataque soviético a Polonia encontró una amplia resonancia en la prensa española, ${ }^{43} \mathrm{e}$ incluso algunos periódicos lo comentaron como la cuarta partición, sería vano buscar una crítica explícita a Stalin por sus acciones ${ }^{44}$. España deliberadamente trató de no comentar estos eventos demasiado abiertamente, a fin de no empeorar las relaciones con el Tercer Reich. Esta actitud temerosa del Gobierno español fue apreciada por el mismo papa Pío XII, quien reunido con el embajador español ante la Santa Sede, le manifestó que la radio Verdad, que emitía todos los días a las 20.45 horas en septiembre de 1939, dejó de atacar la Unión Soviética e incluso comenzó a proporcionar información favorable a Moscú. ${ }^{45}$

El silencio de los españoles ante la invasión soviética de Polonia fue también objeto de crítica por parte de Portugal. Hablando con Ramón Serrano Suñer, ministro del Interior y concuñado de Franco, Teotónio Pereira le espetó que no entendía las razones de aquel comportamiento. Le criticó también que, como responsable del control de la prensa, hubiese permitido la publicación de un artículo que valoraba la situación de Bielorrusia y Ucrania como "normalizada". Serrano Suñer se defendió argumentando que los responsables de la tragedia polaca eran principalmente Gran Bretaña y Francia, y que en España se le daba suficiente importancia a la cuestión de la amenaza resultante de la alianza entre Alemania y la Unión Soviética. Pero resultaba evidente que España comenzó a tomar una posición mucho más pasiva de lo que desearía el embajador portugués. ${ }^{46}$ Por otra parte, Antonio de Oliveira Salazar notó una falta de

\footnotetext{
41 «Crónica Internacional », en Arriba, 09/09/1939, p. 6. La falsedad de la primera frase deriva de la información tendenciosa proporcionada por las agencias de noticias alemanas; la capitulación de Varsovia se produjo el 28 de septiembre de 1939.

42 GARRIGA, Ramón: La España de Franco..., p. 118.

43 "Después de entrar en Polonia, las tropas rusas se han encontrado con los alemanes en Brest-Litovsk", en La Vanguardia Española, 19/09/1939, p. 4.

44 ABC, 19/09/1939

45 MARQUINA BARRIO, Antonio: Diplomacia vaticana y la España de Franco, Madrid, CSIC, Instituto Enrique Florez, 1983, p. 468.

46 DAPE, vol. VI, p. 84: Pereira a Salazar, 28/09/1939.
} 
respuesta española a la agresión soviética, y el abandono del tono anti-comunista de las declaraciones oficiales. ${ }^{47}$

No hay duda de que los portugueses podían criticar la política de Madrid sin temor, pues la posición internacional de su país era mucho más cómoda que la española. Ubicada en el extremo occidental de Europa, Portugal contaba con un aliado histórico, el Reino Unido, y sólo un país vecino, con el cual mantenía además relaciones muy amistosas, lo que le permitía dar a conocer los crímenes cometidos en Polonia. España, sin embargo, no era suficientemente fuerte como para llevar a cabo su política exterior sin tener en cuenta condiciones previas, esto es, las derivadas de la Guerra Civil, fuente inevitable de deuda, tanto moral, como económica. Entrar en conflicto con el Tercer Reich hubiese significado para España un suicidio político, de ahí que Madrid decidiese no manifestar una clara oposición contra la alianza de Berlín y Moscú. Como acertadamente señaló el embajador portugués, lo que aproximaba España a Alemania no era amor "sino la convicción del poder" de ésta. ${ }^{48}$

El comportamiento del Caudillo, prudente en este sentido, era visible también para los países del Eje. El embajador de Italia en España, Gastone Gambara, reconoció a mediados de septiembre de 1939, en conversación con von Stohrer, que Franco ya había superado la consternación generada por la cooperación entre Alemania y la Unión Soviética y ahora estaba mucho más dispuesto a cooperar con Berlín y Roma. También mencionó que el Caudillo se había distanciado inicialmente debido al hecho de que "el pueblo español" era contrario a los comunistas, sobre todo porque los trágicos recuerdos de la Guerra Civil eran aún demasiado recientes, y porque la Iglesia Católica consideraba Moscú como el Anticristo, lo que impedía cualquier compromiso. ${ }^{49}$

Todo lo hasta aquí apuntado no quiere decir que España guardase silencio por completo y que no reaccionase ante lo que estaba ocurriendo en el Oriente. Había muchos políticos españoles conscientes de la amenaza de la sovietización de Europa. Así, desde Londres, el Duque de Alba alertó en sus despachos a Madrid acerca del peligro de la creación de un imperio "de Vladivostok al Rhin". ${ }^{50}$ En varias ocasiones Franco habló en público con bastante claridad sobre el peligro que venía del Este. El primer caso tuvo lugar el 29 de septiembre cuando dijo, en la sesión del Consejo Nacional:

Tenemos conciencia de que en las batallas libradas en tierras de España salvamos el mundo de un gran peligro, como otra vez hemos intentado en la actual crisis de Europa, hablando serenamente a las naciones y realizando gestiones insistentes para evitar el hundimiento de alguna, cumpliendo con ello los deberes que nos imponen la fidelidad a nuestra historia y el pensamiento católico español. ${ }^{51}$

\footnotetext{
47 DAPE, vol. VI, p. 118: Salazar a Monteiro, 9/10/1939.

48 DAPE, vol. VI, p. 87: Pereira a Salazar, 28/09/1939.

49 Documents on German Foreign Policy (en adelante. DGFP), vol. VIII, Washington 1954, p. 100: Mackensen a Ribbentrop, 19/09/1939.

50 Archivo privado del Duque de Alba, Palacio de Liria, Madrid (adelante: PL) Caja 1, n. 4, Duque de Alba a Beigbeder, 1/10/1939, AVILÉS FARRÉ, Juan: "Un Alba en Londres: la misión diplomática del XVII Duque (1937-1945), en Historia Contemporánea, n 16, 1996, p. 170.

51 AZNAR, Manuel: "España y el hundimiento de Polonia”, en Arriba, 29/09/1939, p. 1.
} 
Era indudable que el uso de la expresión alguna nación se refería a Polonia, sobre todo porque a finales de septiembre de 1939 no había más lucha armada que la de Polonia.

Si bien todavía el 29 de septiembre Franco hizo una alusión, sin mencionar el nombre del país a orillas del Vístula explícitamente, ya el 2 de octubre, entrevistado por Manuel Aznar, del diario Arriba, planteó el problema de la amenaza soviética muy abiertamente. Dijo que Polonia debería haber pedido la paz antes de que su ejército fuese completamente destruido, a fin de preservar al menos una parte de su Estado y para evitar las trágicas consecuencias de la entrada del Ejército Rojo en su territorio. Y consideró la agresión soviética como "la entrada de Rusia en Europa" y un acontecimiento de "mucha importancia", que nadie debería ignorar y contra el cual los países occidentales deberían estar unidos. Por tanto, apeló a que se tomaran acciones para evitar que "desde el oriente de Europa no vengan nuevos y más fuertes peligros para el espíritu europeo". Según Franco, para que los países del Viejo Continente pudiesen resistir mejor este peligro, era necesario evitar la guerra en el Oeste y llevar a cabo la mediación entre los polacos y los alemanes. Suponía que esto salvaría al Estado polaco, aunque dispusiese únicamente de una soberanía limitada, lo que le permitiría desempeñar la función de barrera contra la expansión el comunismo. También hizo hincapié en que la necesidad de plantear estas cuestiones se derivaba no sólo de razones de Estado, sino que también tenía carácter ideológico: era una misión histórica específica impuesta a la nación española a causa de su catolicismo. ${ }^{52}$

En esta ocasión, a diferencia de la situación en los primeros días de septiembre de 1939, España tuvo valor suficiente para plantear la cuestión de la mediación en el ámbito internacional. Hubo dos razones principales: la primera fue la agresión soviética del día 17 de septiembre, que confirmó claramente que todas las preocupaciones anteriores de los políticos españoles estaban justificadas; la segunda la constituían las noticias que llegaban de Francia, en el sentido de que ésta respaldaría los intentos de resolver el conflicto tomados por España con apoyo de Portugal.

Pocos días después de la invasión, el embajador español en Francia, José Félix de Lequerica, informó de que en Francia había surgido un grupo de políticos muy influyentes, liderado por el ex primer ministro Pierre Flandin, el ministro de Obras Públicas Anatole de Monzie y el diputado Gastón de Bergery, que comenzó a reclamar, cada vez con más fuerza, que se empezasen las negociaciones con Adolf Hitler. Además, dichos políticos dieron a entender abiertamente a Lequerica que contaban con que Franco apoyase su iniciativa. Aunque nadie de este grupo ejercía todavía función alguna que pudiera determinar la política exterior de la República Francesa, cabe señalar que a menudo aparecían rumores de que Bonnet iba a ser sustituido por Monzie, lo que significaría que las riendas de la diplomacia francesa quedarían en manos de un político acorde con negociar con Hitler. ${ }^{53}$

Las señales que llegaban de Francia causaron que Madrid apoyase incentivos de volver a proponer la mediación. El 1 de octubre de 1939, con motivo del Día del Caudillo, Franco tuvo una conversación con von Stohrer. La reunión comenzó por

\footnotetext{
52 AZNAR, Manuel: "El Caudillo ante Europa en nombre de España”, en Arriba, 03/10/1939.

53 SUÁREZ FERNÁNDEZ, Luis: España, Franco..., p. 120.
} 
un acto de cortesía, es decir felicitaciones por la victoria de Wehrmacht en Polonia y por la declaración de Franco, que había predicho la destrucción del ejército polaco en el segundo día del predominio de Alemania, pero poco después el Caudillo volvió a tomar el tema del peligro que constituía el Este para Europa. El embajador alemán aseguró que, a pesar del Pacto Molotov-Ribbentrop, la actitud del Tercer Reich hacia el comunismo seguía sin cambios y también señaló que, en su opinión, se había producido un cambio significativo en la política de Moscú: el abandono de la idea de provocar una revolución mundial por el principio de actuar de acuerdo con el interés del Estado. A pesar de estas explicaciones, Franco retomó el problema polaco, sugiriendo que la continuación de la existencia del Estado, aunque tuviese una soberanía limitada, reduciría la amenaza soviética. ${ }^{54}$

Cuando el 3 de octubre, en la madrugada, Lequerica envió un telegrama a Madrid informando que de Monzie había instado formalmente al Gobierno francés a comenzar a sondear la opinión de Italia acerca de su voluntad de apoyar la iniciativa de paz, Franco decidió, por fin, hacer una propuesta oficial a Alemania. Aquel mismo día el embajador Magaz, tras recibir instrucciones pertinentes del Palacio de Santa Cruz, ${ }^{55}$ propuso al Secretario de Estado alemán, Ernst von Weizsäcker, la intermediación española en las conversaciones de la paz entre Alemania, Gran Bretaña y Francia.

Magaz declaró entonces muy claramente que el resultado de la mediación debería ser la creación de algún tipo de Estado polaco, ya que en caso contrario, Francia y Gran Bretaña nunca estarían de acuerdo en poner fin a la guerra. El rescate del Gobierno polaco sería para ambos países la única manera de salir del conflicto con la cara lo suficientemente alta como para poder explicar a su opinión pública el sentido de las negociaciones con Hitler. ${ }^{56}$ Resulta evidente que la oferta española no fue sólo contra la guerra, sino también en gran medida a favor de Polonia, ya que preveía conceder una parte de las tierras de la Segunda República a los polacos, y también contra la Unión Soviética, en tanto que el Estado polaco, aunque tuviese una soberanía limitada, iba a constituir un baluarte contra sus ambiciones. Berlín, consciente de que la creación del Estado polaco era una condición sine qua non de cualquier negociación con las democracias occidentales llevada a través de España, ignoró la propuesta de mediación, y en aquella situación los políticos de la Península Ibérica fueron conscientes de que ya nada más podían hacer.

\section{Conclusiones}

La reacción española al estallido de la Segunda Guerra Mundial constituye un retrato perfecto de la posición de Madrid en la escena política internacional tras terminar la Guerra Civil. El hecho de tener como aliados Berlín y Roma, marcó automáticamente las prioridades de la política exterior de su gobierno. La abierta hostilidad de Moscú y la delicada aversión de París hacia el nuevo Caudillo español aumentaban la sim-

54 DGFP, vol. VIII, p. 181-182: Stohrer a Ribbentrop, 01/10/1939.

55 Sede del Ministerio Español de Asuntos Exteriores.

56 DGFP, vol. VIII, p. 203: Memorandum de Weizsäcker, 03/10/1939. 
patía hacia los países del Eje. Por lo tanto, cuando el 1 de septiembre la Wehrmacht invadió Polonia, España, a pesar de la simpatía declarada por el país atacado y por la similitud ideológica resultante del catolicismo y del anticomunismo, no se declaró abiertamente en defensa de Varsovia.

El realismo político y la incertidumbre de la situación fueron las razones por las cuales España no quiso empeorar sus relaciones con el Tercer Reich. Además, éste había ayudado mucho a los franquistas a ganar la Guerra Civil, a la vez que había llegado a configurar, tras no pocos éxitos, un poder fuerte a nivel de Europa. Por ello, el Gobierno español se apartó de los acontecimientos que tenían lugar en Polonia en septiembre de 1939, sobre todo porque había otros países comprometidos, debido a sus obligaciones en virtud de los tratados de alianza, a defender la independencia de la República de Polonia.

Los países europeos respaldaron la actitud de Madrid ya que observaron un enfriamiento de la relación entre España y Alemania debido al Pacto Molotov-Ribbentrop. Vale la pena mencionar aquí que Gran Bretaña y Francia, siendo enemigos del Tercer Reich, no tenían interés en justificar la política del gobierno de Franco ni de ocultar su posible simpatía pro-alemana.

Portugal constituía en realidad la única excepción, ya que criticó la reacción española a los acontecimientos de agosto y septiembre de 1939, juzgándola como demasiado conciliadora. Y, sobre todo, consideraba como negativa la falta de reprobación del Pacto soviético-alemán por parte de Franco, así como el cambio del tono de las declaraciones oficiales, que después del 23 de agosto eran claramente menos anticomunistas. Sin duda, la situación geopolítica favorable de Portugal le daba más oportunidades de presentar su posición de un país ultra anti-comunista. Este país tenía sólo un vecino con el cual mantenía además relaciones amistosas, y en la política exterior desempeñaba el papel de aliado británico tradicional. Tampoco le afectó seriamente la Guerra Civil española, que obligó al gobierno español a apoyarse en Italia y el Tercer Reich, pues el gobierno de Salazar disponía ya de fundamentos bastante fuertes en 1939. De aquella manera, Portugal se encontraba en una situación más favorable para poder demostrar abiertamente su oposición al Pacto MolotovRibbentrop y para criticar a aquellos que, por realismo político, no presentaban su aversión de manera tan abierta.

No hay duda de que España evaluó los acontecimientos de septiembre 1939 como definitivamente negativos. La invasión alemana de Polonia, por la cual el Reino Unido y la vecina Francia se incorporaron a la guerra, provocó que la amenaza del conflicto se acercase a la Península Ibérica. La intervención soviética, a su vez, aumentó la posibilidad de que la influencia de Moscú, considerado en España como el enemigo número uno, se extendiese a otros países de Europa Central y del Este, y con ello una Unión Soviética reforzada constituyese una amenaza más seria para el gobierno de Franco. La intención de protegerse contra este escenario constituyó la base de los planes españoles para lograr la mediación entre las partes en el conflicto. Una condición natural de la paz iba a ser el consentimiento de Alemania para crear una forma de Estado polaco, que constituiría un obstáculo para la difusión de la influencia del comunismo en el Occidente. Sin duda, tal creación no habría sido nada más que una versión polaca del Estado de Vichy, pero indudablemente hubiera sido mejor que 
la ocupación total del país por dos potencias totalitarias y, sobre todo, hubiese reducido las graves pérdidas demográficas del pueblo polaco. Tal vez por estas razones, el proyecto fue rechazado por el lado alemán.

La propuesta española de mediación fue, sin embargo, todo lo que Franco pudo hacer en aquella situación internacional. Siendo consciente de la debilidad de su país y de la necesidad de basar la política exterior en la alianza con el Eje, cuidaba sobre todo de que los acontecimientos que tenían lugar en Polonia, un país lejano, no empeorasen las relaciones con el Tercer Reich. Por lo tanto, de acuerdo con lo que escribió en su informe el ministro Beigbeder, la mediación en la cuestión polaca no era prioritaria para España. Sin embargo, Franco decidió mencionar la situación de Polonia en varias ocasiones durante conversaciones con representantes de Alemania, o mostrar señales amigables hacia Varsovia en sus discursos públicos. Impulsada por el principio del realismo político, España no pudo permitirse más en aquella situación internacional. Cabe destacar que estos esfuerzos de Franco fueron evaluados positivamente en Europa, incluso por los países que desde el 3 de septiembre de 1939 se encontraban en estado de guerra contra el Tercer Reich, en cierto punto aliado de Madrid.

Además, la primera víctima de la invasión alemana, Polonia, disfrutó de una considerable simpatía de los españoles, cuya prueba más tangible fue el respeto por su Gobierno en el exilio y la existencia de una representación del mismo en Madrid. Los españoles sabían que este estado de cosas sería objeto de crítica en Alemania, pero eran conscientes de que -como dijo Beigbeder al embajador de los Estados Unidosnegándose a reconocer al Gobierno polaco en Francia, "se cubrirían de vergüenza". 57

\section{Referencias bibliográficas}

ÁLVAREZ BOLADO, Alfonso: Para Ganar la Guerra, para Ganar la Paz: Iglesia y Guerra Civil: 1936-1939, Madrid, Publicaciones de la Universidad Pontificia Comillas, 1995.

ANDRÉS-GALLEGO, José y PAZOS, Antón (ed.): Documentos de la Guerra Civil, vol. 13 (enero-marzo 1939), Madrid, Consejo Superior de Investigaciones Cientificas, 2010

AVILÉS FARRÉ, Juan: “Un Alba en Londres: la misión diplomática del XVII Duque (19371945), en Historia Contemporánea, n 16,1996 , pp. 163-177.

BOWEN Wayne H.: "Spain and the Nazi occupation of Poland, 1939-44", en International Social Science Review, vol. 82, 2007, pp. 135-148

BURDICK Charles: Germany's Military Strategy and Spain in World War II, New York, Syracuse University Press, 1968.

Correspondência de Pedro Teotónio Pereira para Oliveira Salazar (1931-1939), vol. I, Lisboa 1987.

DILKS David (ed), The Diaries of Sir Alexander Cadogan 1938-1945, New York, G. P. Putnam's Sons, 1972.

DOUSSINAGUE, José María: España tenía razón, Madrid, Espasa - Calpe S.A, 1949.

57 FRUS, 1940, vol. II, p. 794: Weddell a Hull, 5/05/1940. 
GARRIGA, Ramón: La España de Franco. Las relaciones con Hitler, Madrid, G. del Toro Editor, 1976

GÓMEZ-JORDANA, Francisco: Milicia y diplomacia, Burgos, Dossoles, 2002.

MARQUINA BARRIO, Antonio: Diplomacia vaticana y la España de Franco, Madrid, Consejo Superior de Investigaciones Cientificas, Instituto Enrique Florez, 1983.

MORENO JULIÁ, Xavier: Hitler y Franco. Diplomacia en tiempos de guerra (1936-1945), Barcelona, Editorial Planeta, 2007.

MULARSKA-ANDZIAK, Lidia: Hiszpania $w$ polityce Stanów Zjednoczonych $w$ okresie Drugiej Wojny Światowej, Varsovia, 1990

PAYNE Stanley: Franco y Hitler : España, Alemania, la Segunda Guerra Mundial y el holocausto, La Esfera de los Libros, Madrid 2008.

ROS AGUDO, Manuel: La guerra secreta de Franco (1939-1945), Barcelona, Editorial Crítica, 2002.

SUÁREZ FERNÁNDEZ Luis: Franco, España y la Segunda Guerra Mundial, Madrid, Actas, 1997.

TUSELL, Javier: Franco, España y la Segunda Guerra Mundial, Madrid, Ediciones Temas de Hoy, 1995.

- Franco y Mussolini. La política española durante la segunda guerra mundial, Barcelona, Ediciones Península, 1985. 